\title{
Analysis on the Change Characteristics of the Correlation between Land Use Structure and Energy Consumption and Carbon Emissions in Kunming from 1997 to 2017
}

\author{
Li Zhang, Ping Wang* \\ Department of Geography, Yunnan Normal University, Kunming, China \\ Email: zl18787582603@163.com, ^ynwangping@163.com
}

How to cite this paper: Zhang, L., \& Wang, P. (2021). Analysis on the Change Characteristics of the Correlation between Land Use Structure and Energy Consumption and Carbon Emissions in Kunming from 1997 to 2017. Journal of Geoscience and Environment Protection, 9, 155-166. https://doi.org/10.4236/gep.2021.96009

Received: April 19, 2021

Accepted: June 26, 2021

Published: June 29, 2021

Copyright $\odot 2021$ by author(s) and Scientific Research Publishing Inc. This work is licensed under the Creative Commons Attribution International License (CC BY 4.0).

http://creativecommons.org/licenses/by/4.0/

\begin{abstract}
This study takes Kunming City, Yunnan Province, China as the research area, to provide reference basis for revealing the change law of land use structure and energy consumption and carbon emissions in Kunming, optimizing land use structure and realizing the development of low-carbon city. Based on the data of land use structure and energy consumption in Kunming from 1997 to 2017, based on the estimation of total energy consumption carbon emissions, carbon intensity and per capita carbon emissions, the correlation between land use structure and energy consumption carbon emissions in Kunming has been calculated and analyzed in the past 20 years. Results: 1) The total amount of carbon emissions in Kunming has increased significantly in the past 20 years. It increased from $34.46 \times 10^{5} \mathrm{t}$ to $95.09 \times 10^{5} \mathrm{t}$, an increase of about 2.8 times. 2) The types of land use with the highest correlation between land use structure and total carbon emissions of energy consumption, carbon emission intensity and per capita carbon emissions are urban and village and industrial and mining land (0.8258), cultivated land (0.8733) and garden land (0.7971) respectively. 3) The correlation between construction land and total carbon emissions is greater than that of agricultural land. Conclusion: There is a close correlation between land use structure and carbon emissions from energy consumption in Kunming.
\end{abstract}

\section{Keywords}

Kunming City, Land Use Structure, Energy Consumption, Carbon Emissions, Correlation Degree 


\section{Introduction}

In the context of global warming, energy crisis and environmental crisis, it has become the consensus of the international community to control greenhouse gas emissions and promote low-carbon development (Su, Wen, Ding et al., 2016). The Global Carbon Project (GCP) study shows that (GCP., 2018-12-05/2021-03-31). Cumulative carbon emissions from global fossil fuel and land-use changes were $425 \pm 20 \mathrm{GtC}$ and $180 \pm 60 \mathrm{GtC}$, respectively, in 1870-2017. Of these, China's fossil fuel combustion contributed the highest $27 \%$ of global $\mathrm{CO}_{2}$ emissions in 2017 , and land-use change carbon emissions were $1.4 \pm 0.7 \mathrm{GtC}$. The combustion of fossil fuels and land use and other human activities will make the global carbon cycle unbalanced, and the increase of $\mathrm{CO}_{2}$ content in the atmosphere is the main cause of global warming and the intensification of greenhouse effect (Watson \& Verardo., 2000). Land use causes carbon emissions. The main sources of land carbon emissions are human activities on the land and the maintenance and transformation of the land itself (You \& Wu, 2010; Eggleston, Buendia, Miwa et al., 2006). At the same time, land is also an important factor affecting carbon emissions from energy consumption (Zhang, Lai, Huang et al., 2013; Fei, Wu, \& Cheng, 2017). Many scholars have studied carbon emissions from land intensive, land use carbon emission effect, energy consumption and land use structure optimization based on (Analytic Network Process, ANP) method (Li \& Chen, 2013), Gray correlation analysis method (You, Wu, \& Shen, 2010), Data Envelopment Analysis, (DEA) model (Zhu, Mei, \& Chen et al., 2015), and so on. For example, (Zhang, Lai, Huang et al., 2013) studied the carbon emission intensity of the transformation of land use type in different regions of China, and found that there are great regional differences in the carbon emission intensity of the transformation of land use type. By calculating the carbon emissions of different land use types in Xinjiang, (Tang, Ma, \& Su, 2016) found that the total land use carbon emissions and per capita carbon emissions showed a trend of increasing year by year (You, Wu, \& Shen, 2010). Based on the gray correlation analysis method, the correlation degree between land use structure and carbon emissions from energy consumption is measured, and the correlation degree between them is found to be different. It is feasible to adjust land use structure to control carbon emissions from energy consumption (Ali \& Nitivattananon, 2012). Ali and Nitivattananon used the Pakistan metropolis as a research area. They research on the relationship between land use change, carbon emissions and energy consumption found that there is a correlation between the three (Meng, Cui, \& Wang, 2018). And others measured the relationship between land use structure and carbon emissions from energy consumption in Urumqi and found that adjusting land use structure can control the increase of carbon emissions. Previous studies have provided a large number of research methods and technologies for the analysis of the land use carbon emission effects. The research on land use and carbon emissions mainly focuses on direct carbon emissions (Yang et al., 2010; Du et al., 2010; Qu, Lu, \& Feng, 2011; Ge, Dai, He et al., 2008). The study of combining land use with direct carbon emis- 
sions and indirect carbon emissions is inadequate, and the time scale of the study is short (Lu, Lei, \& Zhang et al., 2014; Qu, Zhai, \& Zhang, 2019; Li, Huang, \& Zhen, 2008). It is difficult to reveal the changing characteristics of regional land use carbon emissions.

As one of the first low-carbon pilot cities in China, Kunming is also one of the central cities of central Yunnan urban agglomeration and one of the important central cities in the western region (TSC., 2016-09-21/2021-03-31). So it is imperative to realize urban low-carbon development. Based on the data of land use and energy consumption from 1997 to 2017, the correlation measure and variation law between land use structure and carbon emissions from energy consumption in Kunming is analyzed by using multi-low-carbon index analysis and gray theory model, providing scientific basis for rational adjustment of land use structure and development of low-carbon city in Kunming.

\section{Overview of the Study Area}

Kunming City $\left(102^{\circ} 10^{\prime}-103^{\circ} 40^{\prime} \mathrm{E}, 26^{\circ} 23^{\prime}-26^{\circ} 22^{\prime} \mathrm{N}\right)$ is located in the middle of the Yunnan-Guizhou Plateau, Yunnan Province is the political, economic, cultural, transport hub, At the junction of the North-South International Passage and the third East-West Asian-European Mainland Bridge, China is facing South Asia, Southeast Asia open "bridgehead" city (SF, 2016). In 2017, 21,473 km², of Land in Kunming Population 6.783 million, GDP worth 485.764 billion yuan, an increase of $9.7 \%$.

\section{Data Sources and Research Methods}

\subsection{Data Sources}

The first-class land use type change data from Kunming Land and Resources Bureau. The data of energy consumption, total GDP and total population are derived from the 1998-2018 Kunming Statistical Yearbooks (Kunming Bureau of Statistics, 1998-2018). According to the actual situation of energy consumption in Kunming, seven kinds of energy sources, raw coal, coke, gasoline, kerosene, diesel oil, fuel oil and liquefied petroleum gas, all of them are been selected for carbon emission calculation and analysis. Various carbon emission factors for energy consumption are derived from The 2006 IPCC Guidelines for National Greenhouse Gas Inventories (IPCC, 2006).

\subsection{Research Methods}

The data related to land use and energy consumption were collected and sorted, and the total amount of carbon emissions from energy consumption, carbon emission intensity and per capita carbon emissions were measured by multi-low-carbon index analysis method, and the correlation characteristics between land use structure and carbon emissions from energy consumption in Kunming were measured and analyzed by gray correlation analysis method. 


\subsubsection{Carbon Emission Estimation Methodology}

Carbon emissions from land use are composed of direct carbon emissions and indirect carbon emissions, the former is the carbon emissions generated by land use type transformation and conservation, and the latter mainly refers to the of carbon emissions produced by human production and life on different land use types.

1) Direct carbon emission calculations

Based on the research results of previous scholars, the carbon emission of cultivated land, garden land, woodland, forage land and unused land are calculated by direct carbon emission method. Calculation formula:

$$
E_{A}=\sum e_{j}=\sum B_{j} \times \theta_{j}
$$

Of which, $E_{A}$ is total carbon emissions; $e_{j}$ is the carbon emissions for the $j$ type of land; area corresponding to the $B_{j}$ type of land; $\theta_{j}$ is the carbon emission coefficient for the $j$ type of land, The carbon emission coefficient of each land use type is determined by reference of (Cai, Kang, \& Htsuruta, 2005; He et al., 2006; Xiao et al., 2012; Fang et al., 2007; Lai \& Huang, 2011), and other scholars, Carbon emission factors for 5 land types are cultivated land (0.504), garden land $(-0.210)$, woodland $(-0.581)$, pasture land $(-0.021)$ and unused land $(-0.005)$. The positive value is emission and the negative value is absorption.

2) Calculation of carbon emissions from energy consumption

Using the method of carbon emission coefficient of IPCC energy, the carbon emission of energy consumption is calculated by determining the carbon emission coefficient of all kinds of energy. The formula is as follows:

$$
C=\sum C_{i}=\sum M_{i} E_{i}
$$

Of which, $C$ is the total amount of energy consumption carbon emissions; $C_{i}$ is the $i$ energy consumption carbon emissions; $M_{i}$ is the $i$ energy consumption; $E_{i}$ is the $i$ energy carbon emission coefficient. The carbon emission coefficients of various fossil energy sources are shown in Table 1.

3) Total carbon emissions $(Q)$, direct carbon emissions $\left(E_{A}\right)$, carbon emissions from energy consumption $(C)$.

\subsubsection{Land Use Structure and Energy Consumption Carbon Emission Correlation Measurement Model}

Correlation degree analysis based on gray system can quantitatively describe and compare the development and change situation of the system, and can restriction (Wang, Huang, \& Chen, 2009). Of poor information and limited sample between land use structure and carbon emissions from energy consumption. The correlation measurement model of land use structure and carbon emissions from energy consumption is as follows:

Table 1. Various types of energy consumption and carbon emission system (IPCC, 2006).

\begin{tabular}{ccccccc}
\hline Raw coal & Coke & Gasoline & Kerosene & Diesel oil & Fuel oil & liquefied petroleum gas \\
\hline 0.7559 & 0.8550 & 0.5538 & 0.5714 & 0.5921 & 0.6185 & 0.5042 \\
\hline
\end{tabular}


If there are $p$ time series, the comparison sequence is:

$$
\left\{X_{1}^{0}(t)\right\},\left\{X_{2}^{0}(t)\right\}, \cdots,\left\{X_{p}^{0}(t)\right\}, t=1,2, \cdots, n
$$

If there are $q$ master sequence, the reference sequence is:

$$
\left\{Y_{1}^{0}(t)\right\},\left\{Y_{2}^{0}(t)\right\}, \cdots,\left\{Y_{q}^{0}(t)\right\}, t=1,2, \cdots, n
$$

Calculate the correlation coefficient. After the data is dimensionless, the comparison series is marked as $\left\{X_{i}^{0}(t)\right\}$, and the reference series is marked as $\left\{Y_{j}^{0}(t)\right\}$, then at time $t=k,\left\{X_{i}^{0}(k)\right\}$ The correlation coefficient $\varepsilon_{i j}(k)$ with $\left\{Y_{j}^{0}(k)\right\}$ is calculated as follows:

$$
\varepsilon_{i j}(k)=\frac{\Delta \min +\rho \Delta(\max )}{\rho \Delta \max +\left|\left\{Y_{j}^{0}(k)\right\}-\left\{X_{i}^{0}(k)\right\}\right|}
$$

Of which, $\Delta(\max )$ and $\Delta(\min )$ respectively represent the maximum and minimum of all absolute differences in all comparison sequences, $\rho$ is the resolution coefficient, $\rho \in(0 \sim 1)$, In this study $\rho$ is 0.5 , The correlation degree is obtained by calculating the average value of the relation coefficient of the two comparison sequences, that is:

$$
r_{i j}=\frac{1}{n} \sum_{k=1}^{n} \varepsilon_{i j}(k)
$$

\section{Results and Analysis}

\subsection{Dynamic Change Characteristics of Land Use Structure in Kunming from 1997 to 2017}

From Table 2, we can see that the characteristics of the outstanding changes in the three periods of 1997-2007, 2007-2017, 1997-2017 are as follows: the maximum dynamic degree of urban village and industrial and mining land is $2.97 \%$, $2.69 \%$ and $7.25 \%$, followed by transportation land, the dynamic degree is $2.68 \%$, $1.16 \%$ and $4.47 \%$, respectively. During these 20 years, urban and rural land, industrial and mining land and transportation land showed a rapid growth trend, indicating that the intensity of land development and utilization in Kunming increased. As a result, urban and rural land, industrial and mining land and transportation land area dynamic change range is large.

Table 2. Land use dynamics in Kunming 1997-2017.

\begin{tabular}{cccc}
\hline Land type & $1997-2007$ & $2007-2017$ & $1997-2017$ \\
\hline Arable land & $-0.08 \%$ & $-0.21 \%$ & $-0.37 \%$ \\
Garden & $1.06 \%$ & $1.06 \%$ & $2.35 \%$ \\
Woodland & $-0.15 \%$ & $-0.21 \%$ & $-0.35 \%$ \\
Grassland & $0.63 \%$ & $-0.13 \%$ & $0.49 \%$ \\
Towns, villages and industrial and mining land & $2.97 \%$ & $2.69 \%$ & $7.25 \%$ \\
Land for transportation & $2.68 \%$ & $1.16 \%$ & $4.47 \%$ \\
Land for waters and water conservancy facilities & $-0.34 \%$ & $1.01 \%$ & $0.60 \%$ \\
Unused land & $-0.98 \%$ & $-0.33 \%$ & $-1.25 \%$ \\
\hline
\end{tabular}


From 1997 to 2017, the area of four types of land used for urban villages, industrial and mining land, transportation land, garden land, and grassland all showed an increasing trend. Among them, the largest increase was urban villages and industrial and mining land $\left(8.04 \times 10^{4} \mathrm{hm}^{2}\right)$, followed by transportation land $\left(1.92 \times 10^{4} \mathrm{hm}^{2}\right)$ and garden land $\left(1.62 \times 10^{4} \mathrm{hm}^{2}\right)$; the area of unused land, cultivated land and forest land decreased by $4.33 \times 10^{4} \mathrm{hm}^{2}, 2.31 \times 10^{4} \mathrm{hm}^{2}$ and 7.73 $\times 10^{4} \mathrm{hm}^{2}$ respectively (Figure 1 ).

\subsection{Analysis on the Change Characteristics of Energy Consumption Carbon Emission in Kunming from 1997 to 2017}

As can be seen from Table 3, the total carbon emissions in Kunming increased greatly from $34.46 \times 10^{5} \mathrm{t}$ in 1997 to $95.09 \times 10^{5} \mathrm{t}$ in 2017 , which increased by about 2.8 times. The first stage was from 1997 to 2013 . The total carbon emission

Table 3. Estimated results of total carbon emissions, carbon emission intensity and per capita carbon emissions in Kunming from 1997 to 2017.

\begin{tabular}{|c|c|c|c|}
\hline years/a & $\begin{array}{c}\text { Total carbon } \\
\text { emissions } / 10^{5} \mathrm{t}\end{array}$ & $\begin{array}{l}\text { Carbon intensity } \\
\text { (t/100 million yuan) }\end{array}$ & $\begin{array}{c}100 \text { million yuan } \\
\text { ( } t / \text { Ten thousand people) }\end{array}$ \\
\hline 1997 & 34.46 & 7071.78 & 8978.93 \\
\hline 1998 & 38.71 & 7064.18 & 9935.15 \\
\hline 1999 & 41.97 & 7090.52 & 8865.40 \\
\hline 2000 & 43.60 & 6962.43 & 9067.37 \\
\hline 2001 & 47.76 & 7095.49 & 9795.88 \\
\hline 2002 & 53.77 & 7365.50 & $10,867.62$ \\
\hline 2003 & 63.13 & 7755.61 & $12,606.38$ \\
\hline 2004 & 72.94 & 7741.67 & $14,502.79$ \\
\hline 2005 & 79.36 & 7475.64 & $13,040.01$ \\
\hline 2006 & 93.66 & 7757.64 & $15,223.86$ \\
\hline 2007 & 108.55 & 7725.94 & $17,527.55$ \\
\hline 2008 & 109.41 & 6441.24 & $16,574.30$ \\
\hline 2009 & 118.22 & 6433.68 & $18,824.25$ \\
\hline 2010 & 134.65 & 6350.46 & $20,910.79$ \\
\hline 2011 & 141.46 & 5636.71 & $21,808.38$ \\
\hline 2012 & 145.73 & 4839.67 & $22,306.66$ \\
\hline 2013 & 149.44 & 4375.59 & $22,714.71$ \\
\hline 2014 & 78.99 & 2127.30 & $11,920.68$ \\
\hline 2015 & 129.73 & 3269.45 & $19,429.71$ \\
\hline 2016 & 107.24 & 2469.87 & $15,939.80$ \\
\hline 2017 & 95.09 & 1957.53 & $14,018.85$ \\
\hline
\end{tabular}




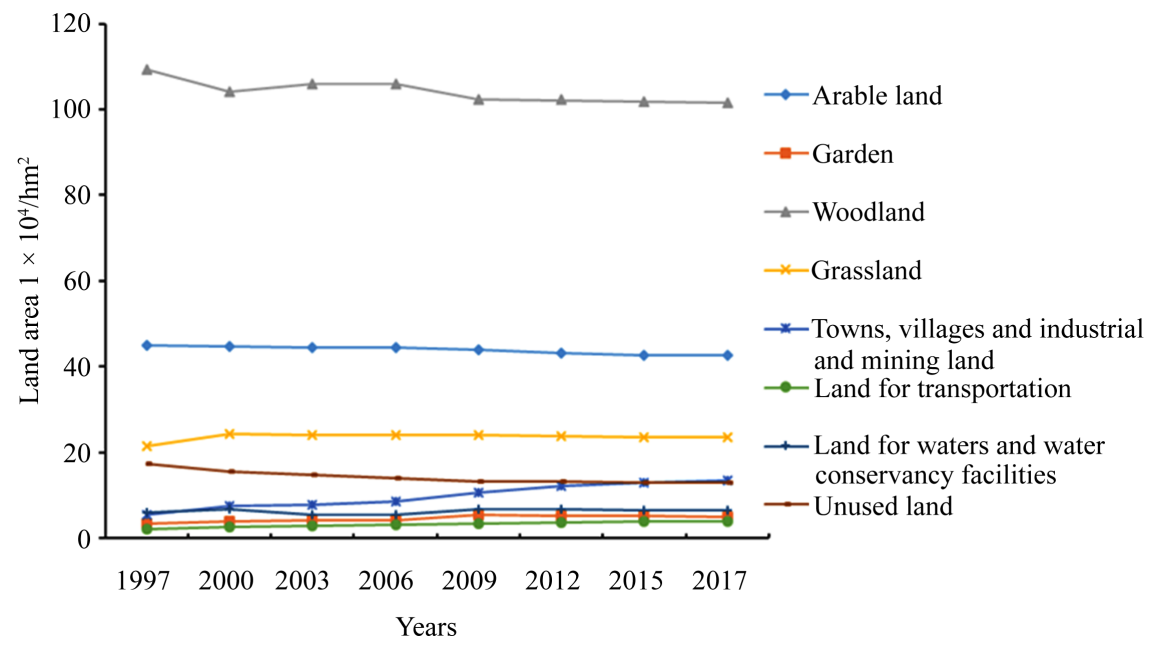

Figure 1. Land use changes in Kunming 1997-2017.

showed a sustained and rapid growth trend, from $34.46 \times 10^{5} \mathrm{t}$ in 1997 to 149.44 $\times 10^{5} \mathrm{t}$ in 2013. The second stage is from 2013 to 2017, the total carbon emission shows a fluctuating downward trend, from $149.44 \times 10^{5} \mathrm{t}$ in 2013 to $95.09 \times 10^{5} \mathrm{t}$ in 2017. Among them, 2014 declined most sharply, only $78.99 \times 10^{5} \mathrm{t}$, mainly because since the 13th five-year Plan, the municipal government has implemented measures to save energy and reduce consumption, and low-carbon development measures. Carry out low-carbon pilot work to strictly control the total coal consumption, natural forest protection, public welfare forest construction, inefficient forest transformation, reduce pollutant emissions, promote energy-saving measures and so on. By the end of 2014, the energy consumption per unit of GDP in the city had dropped by $22.7 \%$ compared with 2010 . The carbon emission intensity decreased from $7071.78 \mathrm{t} / 100$ million yuan in 1997 to $2127.30 \mathrm{t} / 100$ million yuan in 2017 , which can be divided into two stages. The first stage is from 1997 to 2007, the carbon emission intensity shows a small fluctuating upward trend, during this stage, Kunming has a rapid process of urbanization and industrialization, and the economy is developing rapidly. at the same time, it is accompanied by a large increase in carbon emissions. The second stage is from 2007 to 2017, the carbon emission intensity decreased significantly, from $7725.94 \mathrm{t} / 100$ million yuan in 2007 to $1957.53 \mathrm{t} / 100$ million yuan in 2017 . At this stage, the economy of Kunming is in a stage of rapid development, and the gross national product ((GDP)) increases rapidly, from 140.505 billion yuan to 485.764 billion yuan, and the growth rate is faster than the total carbon emissions, resulting in a sharp reduction in carbon emission intensity. The per capita carbon emissions increased first and then decreased. From 1997 to 2013, the per capita carbon emissions increased significantly, from $8978.93 \mathrm{t} / \mathrm{Ten}$ thousand people in 1997 to 22,714.71 t/Ten thousand people in 2013. At this stage, economic growth has become a factor driving the increase of per capita carbon emissions. The inflection point occurred in 2013 and then began to fall, due to the decline in total carbon emissions and the optimization of energy structure and the improvement of energy efficiency. 


\subsection{Correlation Analysis of Land Use Structure and Carbon Emission in Kunming from 1997 to 2017}

\subsubsection{Analysis of Static Characteristics of Correlation Degree between Land Use Structure and Carbon Emissions}

From Table 4, the correlation between land use structure and total carbon emissions is in the following order: urban and village land and industrial and mining land $(0.8258)>$ transportation land $(0.8169)>$ garden land $(0.8006)>$ grassland $(0.6901)>$ water and water conservancy facilities land $(0.6730)>$ cultivated land $(0.6548)>$ forest land $(0.5713)>$ unused land $(0.5582)$. It can be seen that urban and village and industrial and mining land is the most related to the total carbon emissions, followed by transportation land and garden land, the correlation degree is more than 0.8 , indicating that the correlation is high. Cultivated land and forest land account for a large proportion of the total land area, and the change trend of their area is close to that of carbon emission intensity, indicating that cultivated land and forest land are closely related to the carbon emission intensity of energy consumption in the process of utilization. In addition, the correlation between unused land, grassland, water area and water conservancy facilities land, garden land, transportation land, urban and village land, industrial and mining land and carbon emission intensity is more than 0.6 , which has a high correlation and has a great influence on the change of carbon emission intensity. The order of correlation between land use structure and per capita carbon emissions is as follows: garden land $(0.7971)>$ transportation land $(0.7824)>$ urban and village and industrial and mining land $(0.7810)>$ grassland $(0.7652)>$ water and water conservancy facilities land $(0.6457)>$ cultivated land $(0.6287)>$ forest land $(0.6190)>$ unused land (0.5783). Garden land has the greatest correlation with per capita carbon emissions, followed by transportation land, with a correlation of $>0.7$ and high correlation. Garden land, as a functional land for carbon sequestration, can play a role in carbon sequestration to a certain extent around Kunming city. the average level of energy consumption and the level of impact on the surrounding environment in an area can be reflected in per capita carbon emissions, compared with carbon sink land, grassland, woodland and unused land. The correlation between transportation land, urban and village land, industrial and mining land as carbon source land and per capita carbon emissions should be higher.

Table 4. Calculation results of correlation between land use structure and carbon emissions in Kunming from 1997 to 2017.

\begin{tabular}{ccccccccc}
\hline Project & arable & Garden & woodland & Grassland & $\begin{array}{c}\text { Towns, villages } \\
\text { and industrial } \\
\text { and mining land }\end{array}$ & $\begin{array}{c}\text { Land for } \\
\text { transportation }\end{array}$ & $\begin{array}{c}\text { Land for waters } \\
\text { and water } \\
\text { conservancy } \\
\text { facilities }\end{array}$ & $\begin{array}{c}\text { Unprofitable } \\
\text { Land use }\end{array}$ \\
\hline $\begin{array}{c}\text { Total carbon emissions } \\
\text { Carbon intensity }\end{array}$ & 0.6548 & 0.8006 & 0.5713 & 0.6901 & 0.8258 & 0.8169 & 0.6730 & 0.5582 \\
$\begin{array}{c}\text { Carbon emissions } \\
\text { per capita }\end{array}$ & 0.6287 & 0.7971 & 0.6190 & 0.7652 & 0.7810 & 0.7824 & 0.6457 & 0.859 \\
\hline
\end{tabular}




\subsubsection{Analysis of Dynamic Characteristics of the Correlation between Land Use Structure and Carbon Emissions}

The correlation coefficient between agricultural land and carbon emission in each year is obtained by adding the correlation coefficient between cultivated land, garden land, woodland, forage land and energy consumption carbon emission. Meanwhile, the correlation coefficient between construction land and carbon emissions in each year can be obtained. As can be seen from Figure 2, the correlation coefficient between agricultural land, construction land and energy consumption carbon emissions in Kunming fluctuates obviously from 1997 to 2017, but the overall change trend is similar. This dynamic change characteristic is closely related to the continuous expansion of construction land and the continuous reduction of agricultural land. Based on the correlation coefficient of construction land and agricultural land, the correlation between construction land and carbon emissions can be calculated, which is that construction land (0.73) is higher than agricultural land (0.66). From the current process of urban construction and development, construction land plays a major role in the contribution rate of energy consumption and carbon emissions, while agricultural land plays a secondary role.

\section{Conclusion}

Multi-low-carbon index analysis and gray correlation analysis are used to analyze the correlation between land use structure and energy consumption and carbon emissions in Kunming from 1997 to 2017. The conclusions are as follows: 1) The land use structure in Kunming has changed significantly from 1997 to 2017. Among them, the largest dynamic attitude of land use is urban and village land and industrial and mining land (7.25\%), followed by transportation land (4.47\%). The area of unused land, cultivated land and woodland decreased by $8.04 \times 10^{4} \mathrm{hm}^{2}$ and $1.92 \times 10^{4} \mathrm{hm}^{2}$, respectively, while the area of unused land, cultivated land and forest land decreased by $4.33 \times 10^{4} \mathrm{hm}^{2}, 2.31 \times 10^{4} \mathrm{hm}^{2}$ and $7.73 \times 10^{4} \mathrm{hm}^{2}$, respectively. 2) From 1997 to 2017, the total carbon emissions of Kunming showed an increasing trend, from $34.46 \times 10^{5} \mathrm{t}$ in 1997 to $95.09 \times 10^{5} \mathrm{t}$ in 2017 , an increase of about 2.8 times. 3) The types of land use

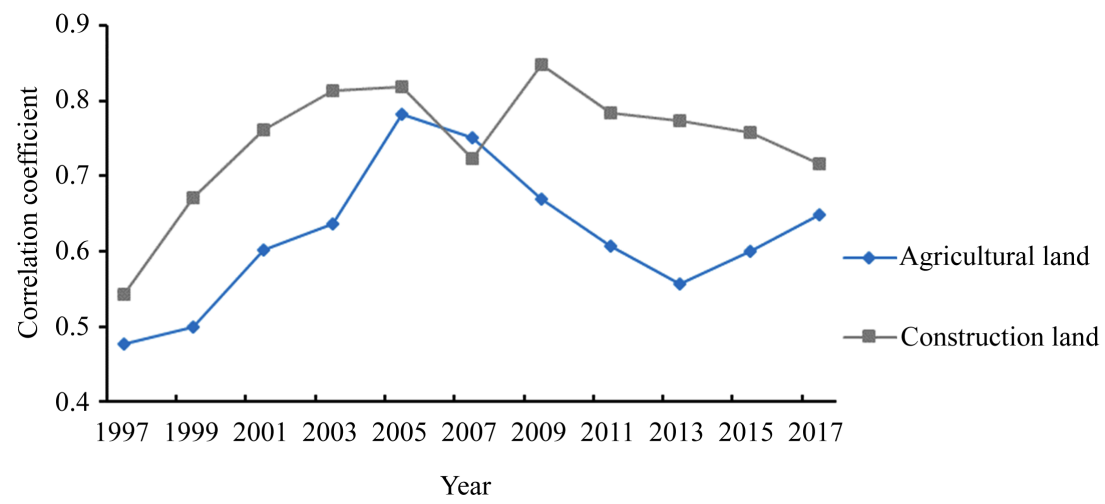

Figure 2. Trends of correlation coefficient of agricultural land, construction land and total carbon emission in Kunming 1997-2017. 
with the highest correlation between land use structure and total carbon emissions of energy consumption, carbon emission intensity and per capita carbon emissions are urban and village and industrial and mining land (0.8258), cultivated land (0.8733) and garden land (0.7971). 4) The correlation between construction land and total carbon emissions (0.73) is higher than that of agricultural land (0.66). 5) There is a close relationship between land use structure and energy consumption and carbon emissions in Kunming.

\section{Recommendation}

As a national excellent tourist city and a low-carbon pilot city, Kunming regards the development of a low-carbon economy and the construction of a low-carbon city as the direction of Kunming's sustainable economic and social development, and seeks a balance between economic development and environmental protection. Rational use of the existing land structure to reduce carbon emissions, improve land use efficiency, and realize the healthy and sustainable development of Kunming's economy is the only way for Kunming's economic development.

1) Use the land structure rationally to improve the efficiency of land use. In the process of urbanization in Kunming, it is necessary to strictly approve construction land, control the large-scale expansion of construction land, and ensure gardens, arable land, grassland, woodland, etc. The holding area of the land strengthens the restoration and construction of wetlands, in order to increase the carbon sink capacity of the city.

2) Optimize the industrial structure, give priority to the development of low-carbon industries, increase the development and utilization of new energy industries, eliminate outdated production capacity, and optimize the energy structure. Carry out research and development and use of new energy fuels, increase the proportion of alternative energy sources, and reduce energy consumption. Focus on eliminating the production capacity of black smelting, non-ferrous smelting, and coke with backward production industries and equipment. Take advantage of Kunming's geographical location to promote the construction of the solar energy industry; accelerate the construction of natural gas infrastructure and gas replacement, improve coal energy efficiency, and reduce high-carbon energy consumption.

3) Appropriately strengthen the taxation of related carbon emissions and build a green and healthy new Kunming. If Kunming wants to reduce the city's energy consumption and total carbon emissions, in addition to introducing relevant measures to limit carbon emissions, it should also strengthen its work on carbon emissions taxation. Measures to increase carbon emissions taxation can be used to limit the total carbon emissions of energy consumption in Kunming, so as to encourage relevant enterprises to reduce their carbon emissions and ultimately achieve the goal of low-carbon sustainable development.

\section{Funded Project}

National Natural Science Foundation of China "Ecology Security Evaluation and 
Early Warning Research in Central Yunnan” (41561048).

\section{Conflicts of Interest}

The authors declare no conflicts of interest regarding the publication of this paper.

\section{References}

Cai, Z. C., Kang, G. D., \& Htsuruta, A. (2005). MOSIER Estimate of $\mathrm{CH}_{4}$ Emissions from Year-Round Flooded Rice Fields during Rice Growing Season in China. Pedosphere, 15, 66-71.

Du, G. Y. (2010). Research on the Impact of Construction Land on Carbon Emissions. China Land Science, 24, 32-36.

Eggleston, H. S., Buendia, L., Miwa, K. et al. (2006). 2006 IPCC Guidelines for National Greenhouse Gas Inventories (pp. 27-43). Prepared by the National Greenhouse Gas Inventories Programme. IGES, Japan.

Fang, J. Y., Guo, Z. D., Park, S. L. et al. (2007). Estimation of China's Terrestrial Vegetation Carbon Sink from 1981 to 2000. Science in China (Series D: Earth Science), No. 6, 804-812. https://doi.org/10.1007/s11430-007-0049-1

Fei, L. C., Wu, C. F., \& Cheng, J. M. (2017). The Carbon Effect of Rural Land Consolidation and Its Policy Response. Resources Science, 39, 2073-2082.

GCP-Carbon Budget (2018-12-05/2021-03-31).

https://www.globalcarbonproject.org/index.htm

Ge, Q. S., Dai, J. H., He, F. N. et al. (2008). Research on Land Use, Land Cover Change and Carbon Cycle in China in the Past 300 Years. Science in China (Series D: Earth Sciences), 38, 197-210.

Ali, G., \& Nitivattananon, V. (2012). Exercising Multidisciplinary Approach to Assess Interrelationship between Energy Use Carbon Emission and Land Use Change in Metropolitan City of Pakistan Metropolitan City of Pakistan. Renewable and Sustainable Energy Reviews, 16, 775-786. https://doi.org/10.1016/j.rser.2011.09.003

He, Y. (2006). Research on the Carbon Cycle of China's Climate and Terrestrial Ecosystems (pp. 141-152). Beijing: Meteorological Press.

IPCC (2006). 2006 IPCC Guidelines for National Greenhouse Gas Inventories.

Kunming Bureau of Statistics (1998-2018). Kunming Statistical Yearbook. Beijing: China Statistics Press.

SF Sina Finance (2016). Kunming Has the Policy Advantages and Unique Advantages of Opening Up the Western Region. http://www.sina.com.cn

Lai, L., \& Huang, X. J. (2011). Research on the Carbon Emission Effects of Land Use in China (pp. 62-75). Nanjing: Nanjing University Press.

Li, K. Q., \& Chen, Y. R. (2013). Evaluation of Land Intensive Use in Nanjing under the Concept of Low Carbon. China Land Science, 27, 61-66.

Li, Y., Huang, X. J., \& Zhen, F. (2008). Analysis of Carbon Emission Effects of Different Land Use Patterns in Jiangsu Province. Transactions of the Chinese Society of Agricultural Engineering, 24, 102-107.

Lu, C., Lei, G. P., Zhang, H. et al. (2014). Carbon Emission Effect Analysis of Different Land Use Types in Harbin, Heilongjiang Province. Research on Soil and Water Conservation, 21, 245-250.

Meng, M., Cui, X. Y., \& Wang, Z. Q. (2018). Research on Correlation Measurement be- 
tween Land Use Structure and Carbon Emissions in Urumqi. Bulletin of Soil and Water Conservation, 38, 178-182+188.

Qu, F. T., Lu, N., \& Feng, S. Y. (2011). The Impact of Land Use Changes on Carbon Emissions. China Population, Resources and Environment, 21, 76-83.

Qu, L. P., Zhai, T. T., \& Zhang, Q. J. (2019). Research on Carbon Emissions from Land Use in Shandong Province Based on Grey Theory Model. Journal of Shandong Agricultural University (Natural Science Edition), 50, 290-296.

Su, J. Z., Wen, M., Ding, Y. H. et al. (2016). Research Progress on Global Warming Slowdown. Atmospheric Sciences, 40, 1143-1153.

Tang, H. S., Ma, H. L., \& Su, Y. (2016) Carbon Emission and Carbon Absorption of Different Land Use Types in Xinjiang. Arid Zone Research, 33, 486-492.

Wang, Q. Q., Huang, X. J., \& Chen, Z. G. (2009). My Country's Primary Energy Consumption Per Capita Carbon Emission Center of Gravity Shift and Analysis of Reasons. Journal of Natural Resources, 24, 833-841.

Watson, R. T., \& Verardo, D. J. (2000). Land Use Change and Forestry (pp. 67-89). London: Cambridge University Press.

Xiao, H. Y., Yuan, X. Z., Li, B. et al. (2012). Research on the Carbon Emission Effects of Land Use Change: Taking Chongqing as an Example. Journal of Chongqing Normal University (Natural Science Edition), 29, 38-42, 115.

Yang, Q. Y. (2010). Land Use Change and Carbon Cycle. China Land Science, 24, 7-12.

You, H. Y., \& Wu, C. F. (2010). The Carbon Emission Efficiency of Land Use and Its Low-Carbon Optimization Based on the Perspective of Energy Consumption. Journal of Natural Resources, 25, 1875-1886.

You, H. Y., Wu, C. F., \& Shen, P. (2010). The Correlation Measurement of Land Use Structure and Energy Consumption Carbon Emission and Its Characteristic Interpretation. China Land Science, 24, 4-9.

Zhang, M., Lai, L., Huang, X. J. et al. (2013). Research on the Carbon Emission Intensity of the Transformation of Land Use Types in China. Resources Science, 35, 792-799.

Zhu, Q. X., Mei, Y., Chen, Y. R. et al. (2015). DEA Model Analysis and Spatial Differentiation Research on the Efficiency of Land Use Structure in Hubei Province Based on Carbon Emissions Estimation. Economic Geography, 35, 176-184. 